\title{
Transformation towards Human Resource Information Systems
}

J. Anitha

Associate Professor, GRGSMS, Coimbatore

Email: anithaj@grgsms.com

M. Aruna

P.S.G.R. Krishnammal College for Women, Coimbatore

Email: yeswecanwin_india@yahoo.com

Accepted 15 February 2015

This paper has explored the various factors namely technological factors, organisational factors, environmental factors and psychological factors that influence in the adoption of Human Resource Information Systems (HRIS). The purpose of the paper is to focus on the factors essential for the adaptability and capability of companies to accept the introduction of information systems like HRIS. The paper is descriptive in nature and the respondents are the users of HRIS in small, medium and large scale companies. The users are the employees, managers and executives of the information technology sector. The techniques of descriptive statistics, one way ANOVA, correlation, and linear regression are used in the analysis to measure the existing level of the influential factors of HRIS. The environmental factor is found to have a profound influence on the adoption of HRIS. This implies that the competitiveness and external pressure are the vital forces for the company to sustain in the global environment and in adopting new technologies. As, this paper has focused only on the respondents from the information technology sector,it can be extended to manufacturing and automobile sectors for a comprehensive model development. The model developed can be considered as a main tool for an organisation for introducing new information systems like HRIS. This also encompasses specific components for successful adoption of HRIS.

Key words - Human resource information system, information system, technological factors, organisational factors, environmental factors, psychological factors, adoption of HRIS

\section{Introduction}

Accurate, timely and relevant information is essential for appropriate decision making. Human Resource Information Systems is a result of merging Human Resource Management and Information Technology in order to make information available as and when necessary. It is a computerized system used to acquire, store, manipulate, analyse and distribute information regarding human resources (Kavanagh et al., 1990). HRIS acts as a major tool for sustainability in business to survive in a globalised environment. DeSanctis (1986) remarked that 'Human Resource Information Systems (HRIS) have become a major MIS sub-function in many large 
corporations'. The surging complications mainly due to ever changing global environment, liberalisation and increasing the number of white collar workers relied on the essentials of HRIS as it paves the way for human resource professional's efficacy (Hennessey, 1979). HRIS becomes an essential development for organisations in managing HR. It not only enables human resources to become strategic but also less bureaucratic.

There are a lot of explicit advantages in this transformation. A survey by Overman (1992) advocates that the potential advantages of HRIS are faster information processing, greater information accuracy, improved planning and program development and enhanced employee communications. Singh et al., (2011) advocates that HRIS is applied in personnel administration, salary administration, leave or absence recording, skill inventory, medical history, performance appraisal, training and development, HR planning, recruitment, career planning and negotiations. Organisations adapt to some form of technology or Information Systems (IS) to upgrade their systems and ease their processes. A number of organisations take up systemising their processes at different levels and different degrees if not the entire routine.

Beckers and Bsat (2002) identified five reasons why companies should use HRIS, namely, increase competitiveness by improving HR practices, produce a greater number and variety of HR operations, shift the focus of HR from the processing of transactions to strategic HRM, make employees part of HRIS, and reengineer the entire HR function. These reviews have a single common outcome that signifies positive impact of HRIS for organisations. This study focuses on various factors that play major roles in adopting the information system. Further, it adds to the knowledge base of HRIS in terms of identifying the predictors and level of impact these factors create in implementing the system.

\section{An overview of HRIS}

HRIS has its origin since the 1960s (Lederer, 1984) when the advancement of computers emerged in a slower pace and with limited functionality. DeSanctis (1986) gave an early definition of HRIS as a 'specialized information system within the traditional functional areas of the organization, designed to support the planning, administration, decision making and control activities of human resource management'. There is increased use of technology and information systems to coordinate HR functions over the years. Research has established that the use of HRIS had consistently increased over the previous years, irrespective of the degree of strategic partnership held by the HR function.

The present study focuses on a thorough literature review that aids in identifying various aspects that influences the adoption of HRIS in organisations. These aspects are categorised in four major groups- namely technological factors, organisational factors, environmental factors and psychological factors according to their nature. The benefits, barriers and operationalization of new systems or technology that influence implementation of the system in an organisation are mainly coalesced as technological factors. The organisational size, span, structure, culture and the organisational related aspects are combined together as organisational factors that influence adapting to new systems like HRIS. The external business environment including the government support and changes in the business arena are considered to be the environmental factors and personal factors which are the characteristics of 
an individual user are considered as psychological factors. The consolidation of the different elements into these four major factors is done mainly by investigating their nature and influence in adapting to a new technology or an information system, in general for adapting to HRIS, in specific.

\section{Technological factors}

Technological factors deal with how far the company operates with the usage of new IT systems. Technology is one of the vital factors that influence adoption of HRIS. Studies (DePietro et al., 1990; Yang et al., 2007) show how the technology context and characteristics influence the adoption of the technology in an organisation. Technological factors identified for this study include the benefits, operationalization of technology and barriers.

The benefits are the advantages which makes the particular system to be effective and efficient. The findings from previous research (Seyal et al., 2007; Alshawi, 2010) emphasise on perceived benefits by the users and the managers as major factors influencing the adoption of IT technologies like CRM, ERP and web technologies. The advantages of advanced IT adoption are decrease in costs and acceleration in productivity (Lymer, 1997). Gains are with respect to improved levels of service quality, efficiency and reliability (Oliveira \& Martins, 2010).

Operationalization of technology deals with operation of any new IT systems and measurement of the same. The operationalization of the technology also influences in adopting a particular system. Chong \& Ooi (2008) and Tan et al. (2009) argue that the operationalization and potential realisation of benefits are major criteria in determining adoption of a new technology. The Operationalization of the technology includes the comfortableness with the usage, quick access to information and reducing paper work (Chong \& Ooi, 2008).

The barriers are the hindrances in the usage of any IT system. The adopters have a great tendency to adhere the innovations in terms of possible gains and barriers (Chau \& Tam, 1997). Barriers include innovation complexity and its compatibility with organizational technology competency and a legacy system that has a huge influence on adoption of technology (Rogers, 2003; Chong \& Ooi, 2008). In the Australian context, Crawford (1998) has identified the inhibiting factors as lack of awareness, inadequate skill of the user, delay in the realization of the benefits and infrastructure issues.

Security related barriers are the obstacles that hinder the particular individual in the usage of IT systems due to security reasons. Lack of security in the forms of confidentiality, integrity, and availability of information assets, is a major barrier to the adoption of ecommerce (Lowry et al., 1999; Poon \& Swatman, 1999; Jeon et al., 2006). Small and medium enterprises face security problems like payment security, privacy and confidentiality of the information or viruses' (Kannabiran \& Dharmalingam, 2012). Many employees still fear to use online payroll mainly due to security reasons (Danilewicz, 1997).

\section{Organisational factors}

Organisational factors are the factors like strong leadership, adequate funding provided by the organisation for the introduction of new IT systems. The organisational factors deduced for this 
study are organisation size, top and middle management support, organisation culture and financial infrastructure.

Organisation size is a significant factor that influences success of an information system in an organisation. Organisational size is the important criterion in innovation adoption (DeLone, 1981; Banerjee \& Golhar, 1994). Larger firms find it easy and viable to go for adoption of new technology than smaller firms due to large scale of operations (Thong, 1999; Yap, 1990). Organisations need to focus on methods that aid in mass acceptance of any new system as acceptance and resistance of new systems is largely influenced by peer pressure and group think. However this may be difficult in small level organisations as the individual factors will play a dominant role here. Moore and Clavadetscher (1985) contend that HR functions are more computerised in larger than smaller firms. Larger firms have adequate financial and technical capability, flexibility and adaptability factors to opt for IT systems to aid decision making unlike SMEs (Yesbank, 2009; Barbosa \& Musetti, 2010).

Any new system can be successful in an organisation only with the involvement of top management. The workforce finds it meaningful and important when they observe that the top management is keen about implementing any new system. Top and middle management support is the support rendered both by top level executives and middle level managers for the implementation of HRIS. Centralisation is the process of having authority of power of decision making particularly in the hands of top management in adoption of new IT technologies. Cavaye and Hussain (2007) have studied that it has a great responsibility for the owners or managers in adopting these technologies as they are the determiners.

Likewise, skills and knowledge in the information system processes are very important for transforming regular work into a systemised work. Expertise is important element in the adoption of new technologies (Kwon and Zmud, 1987). HRIS staff has to upgrade himself with IS knowledge for its adoption (Elliot andTevavichulada, 1999). Lack of sufficient knowledge on IT systems for managerial and technical staffs has an enormous impact on the adoption of technologies (Levy et al., 2001; Wainwright et al., 2005; Hashim, 2007). Hence, top management provides solutions to handle any conflict that arises.

Organisation culture is another important element that influences effective utilization of information systems (Evered et al., 2001). It is the organisational culture that provides new ideas, innovation and flexibility and makes employees adaptable to new information systems and will be accepted by staff and use effectively (Davis, Bagozzi \& Warshaw, 1989; Goodhue, 1995; Bass, 1998). An adaptive and a venturing culture aids in accepting and experimenting new systems enthusiastically.

Financial infrastructure is the firm's financial capability in affording basic facilities, services, and installations needed for the functioning of IT systems. Various research studies (Chinyanyu and Yahsueh, 2011; Srinivasan et al., 2002; Sheth and Sharma, 2005; Wood, 2004) emphasize that lack of IT infrastructure such as poor communication infrastructure, support of IT vendors and skilled manpower as some of the factors that affect in the adoption of advanced IT. Hence, apart from the human related aspects, the financial aspects also need to be stronger in going for new systems. 
Transformation towards Human Resource Information Systems

\section{Environmental factors}

Environment factor is the important element for the determinant of HRIS success (Martinson and Chong 1999). Environmental factors are mainly the external pressure, competitive capability and impact of globalisation which has a direct influence on the adoption of HRIS systems. Research studies by DePietro et al. (1990) and Oliveira and Martins (2010) convey that environmental characteristics includes the way in which the organisation conducts their business, industrial characteristics, government regulations and supporting infrastructure. The globalisation and liberalisation policies make an organisation to sustain with high-tech adaptable technologies like HRIS. Factors like privatisation, competitive capability, government commitment and robust support for the adoption of HRIS systems add support in the adoption of HRIS systems.

Competitive capability indicates how far a company is capable to adapt to introduction of IT systems in the global environment. The organisation has to excel its competitive capability in an effective manner for its survival in a collaborative global environment (Alba et al., 2005). Julien and Raymond (1994) confirm that SMEs mostly opt for IT technologies when there is competition among trading partners or when there is adoption of technology in the industry as a whole.

External pressure is the pressure that a company faces in the global environment. A number of studies have investigated that the available legal or regulatory environment, government support and commitment are the key factors that determine the e-commerce adoption by SMEs (Chang and Cheung, 2001; Jeon et al., 2006). Typically, government play a vital role in emboldening the technology adoption by raising awareness, providing training and support including funding (Chong and Ooi, 2008).

Globalization and liberalization policies have made businesses more competitive and adaptable to the hi-tech environment. Ongori and Migiro (2010) find that the impact of globalization has driven small organisations to sustain in the knowledge economy adaptation on new technological environments, which is very encouraging. Thus globalization have paved way for rapid innovation, easy entry, lesser trade barriers, privatization and liberalization opening up of new economies, increased share in manufacturing of developing countries and provoked a cordial relationship between partners along the value chain (Humprey, 2001; UNDP, 2005; Decker et al., 2006) and hence calls for a broader outlook from the organisations to take up new systems.

\section{Psychological factors}

Psychological factors are essential components to be considered for any new system adoption, which includes emotional feeling, perception, and inner satisfaction that influences organisation's efficiency. Though HRIS improves the performance, it is the user's willingness to use the technology that plays a greater role in its success (Davis, Bagozzi \& Warshaw 1989; Goodhue 1995, Miller and Cardy 2000; Hartel, 2008).

User's perception is a factor that measures how the individual perceive the introduction of new technology and how they implement it. Kossek(1994) and McAfee (2003) suggested 
that perceptions of potential users of a new technology have a critical impact on the success of its implementation. Shrivastava and Shaw (2004) suggests that past HRIS usage has a huge impact on usability perception and the intention to use it consistently which ultimately contributes to the successful HRIS implementation.

User's satisfaction is the particular individual's satisfaction regarding the adoption of any new technology. Studies (Agrell and Gustafson 1996; West et al., 2001) have found that it is the favourable attitude towards new ideas and innovation that paves a great path for the implementation of new systems.

Complexity can be described as the difficulty that the individual faces in the usage of new IT systems. The major obstacles for adoption and implementation of HRIS are user's difficulty to adapt to the changes in work practice and procedure as well as fear of usage of computer technology (Yeh, 1997). According to reactance theory, removal of personal freedom by an authority leads individuals to certain reactions (Brehm, 1966) and these reactions are quite often in the opposite direction (Bushman, 1998). Hence taking care of psychological factors and providing a secured feel is a major responsibility of concern while implementing HRIS.

\section{Adoption of HRIS}

The adoption of HRIS focuses on the success factor in implementing the system. The essentials for the adoption of HRIS are breadth of experience, empowerment and cohesion in the organisation. Studies also suggest that five main factors namely leadership, planning, change management, communication and training also influence the adoption of HRIS or any new systems (Lorenziand Riley, 2000, Kandel, n.d.; Blanchard, 2007). Specific studies on the essential aspects that influence adoption of HRIS and other information systems in general are discussed.

Breadth of experience is the experience that the team members should possess for adoption of any new information technology. The main ingredients for successful development projects are technical skills and team members' experience (Howard, 2001). Empowerment plays a major role in accepting a new system and progressing towards experimenting and adapting to new projects. Behavioural theorists like Hackman and Oldham (1976) have proved that it is the involvement of employees that leads to greater empowerment, job satisfaction and enhances performance.

Group cohesion is the combination of employees who are able to work together and the level of cohesiveness determines every individual member to view the group goal as their own (Steiner, 1972). Other studies have shown that greater level of group cohesion has led to greater interaction among members, greater attainment of goals, greater adhesion to group norms, greater job satisfaction; lower levels of turnover and absenteeism (Shaw,1981; Keller, 1983; Drescher et al., 1985; Iverson and Roy, 1994).

Leadership influences the success of any new system in an organisation. Kavanagh and Thite (2009) contend that the responsibility and recognition of the team's effort leads to successful adoption of HRIS, and good leadership paves for easy adoption of any IS systems. 
Planning includes project scope and strategy to fulfil the project goals (Kavanagh and Thite, 2009). A Project plan may include the functionalities of the system, roles and responsibilities of employees, funding of the project outline and preview of budget constraints (Kavanagh and Thite, 2009). Hence these elements of planning aid in successful adoption of IT systems.

Change Management is the process of making the stakeholders to accept and embrace changes in the already existing systems. Change management is a challenging task for HR leaders in today's scenario. Prager and Overholt (1994) argue that the main cause for failure to implement the new systems is failing to understand and manage the process. It can be understood that projects do not fail often due to technical flaws but also due to people who reject them in an organisation. According to Correll (2005) change management is the main factor for complete adoption of new technology. Therefore the indicators of change management are also included to study the adoption of HRIS in an organisation.

Communication is the process of sharing information to the employee, with regard to the new system that has to be introduced and initiated. Employee communication is an important element for the adoption of a new IT system (Duck, 2001). It is essential to make the employees know about the new changes and also make them understand the usefulness of the changes implemented.

Effective training is necessary in any successful change initiative like introduction of new technology (Kavanagh and Thite, 2009). Ruta (2005) contends that successful companies offer training in early stages of the project to provide information about the new change characteristics and make the employees to accept the new system.

\section{Objectives}

The objective of the study is to understand the contribution of different factors towards the adoption of HRIS. It has described the existing level of user perception of different factors in usage of HRIS and difference in the same as per the company size. The study also intends to study the impact of various factors influencing the adoption of HRIS. This will help organisations to focus on specific aspects while adopting HRIS, that will aid in the implementation process.

\section{Methodology}

The study is descriptive and it is based on primary data. This research has covered to developing a conceptual framework of factors influencing HRIS and validating the same using empirical data. An exhaustive research was made on these factors and an instrument was developed and validated to measure the different variables of HRIS and the related factors. The study was focused on the organisations in the Information Technology Sector in Coimbatore city. A five point Likert-based scales were used in the questionnaire with Strongly Agree, Agree, Neutral, Disagree, and Strongly Disagree options.

\section{Sampling technique}

The sampling frame used in this study was the IT directory list of Coimbatore from ITES companies list. Random sampling has been used in this study. The data collection was made 
from 150 respondents from 15 companies selected randomly from 83 companies. The respondents were randomly selected using system generated random numbers that were used to select employees from the employee register. The respondents were the users of HRIS at junior levels, middle levels and top levels in IT companies. The sample comprised respondents from the medium, small and large companies.

The factor influencing adoption of HRIS in IT organisations including Accenture, Aeon Systems India, Bosch, CAP Digisoft Solutions, CTS, E-Integrity Solutions, HIRIS technologies, K-Logic Softtech Solutions, KG Information Systems, Mezoblanca Solutions India, Pramura Software Limited, Quattro Infotech, RND Softech Private Limited, SIERRA ODC Private Limited and Vestige Technologies were studied. Analysis was done using descriptive methods, ANOVA, correlation and regression to meet the objectives of the study.

\section{Instrument Development and Validation}

The constructs of technological factor, organisational factor, environmental factor and psychological factor were tested for validity and reliability using pilot data. The Cronbach's alpha coefficient was found to be 0.885 , which is statistically significant. This depicts that the factors are uni-dimensional. The cronbach's alpha for the different factors are shown in the Table 1.

Table 1: Reliability Statistics (Value of Cronbach Alpha)

\begin{tabular}{lc}
\hline Factors & Cronbach's Alpha \\
\hline Technological factors & 0.854 \\
Organizational facors & 0.796 \\
Environmental factors & 0.759 \\
Pscyhological factors & 0.775 \\
Adoption of HRIS & 0.814 \\
Overall realiability & 0.885 \\
\hline
\end{tabular}

\section{Analysis and Results}

\section{User Perception of the Factors}

The user perception of the various factors and adoption of HRIS is measured by calculating the mean scores of the items that measured the same. The perception regarding adoption of HRIS is 4 in a scale of 5 that shows that the IS users have a positive perception of adopting and implementing the information system. The Adoption of HRIS is measured using different constituents that lead to effective and successful implementation of it. The components for the adoption of HRIS are discussed earlier in the literature review section. The mean values of user perception of various factors are depicted in Table 2. 
Table 2: Mean values of user perception of various factors affecting HRIS

\begin{tabular}{lrrrc}
\hline \multicolumn{1}{c}{ Different Factors } & Min. & Max. & Mean & Std. Deviation \\
\hline Technological factors & 2.73 & 4.91 & $\mathbf{4 . 2 6}$ & 0.312 \\
Organizational facors & 2.70 & 4.70 & 4.02 & 0.352 \\
Environmental factors & 1.33 & 5.00 & 4.06 & 0.611 \\
Pscyhological factors & 3.00 & 5.00 & 4.13 & 0.404 \\
Adoption of HRIS & 1.64 & 5.00 & 4.00 & 0.526 \\
\hline
\end{tabular}

It clearly depicts from the above table that the mean value $(\mathrm{M}=4.26)$ for technological factor is found to be greater than other factors for adoption of HRIS. Hence, the user's perception in operating HRIS system, its benefits and barriers were found to have greater influence on adoption of HRIS than other factors. Technological Factor deals with how far the company operates with the usage of new IT systems. It includes the benefits, operationalization of technology and barriers. The benefits are the advantages which makes the particular system to be effective and efficient. Operationalization of technology deals with operation of any new IT systems and measuring the technology. The barriers are the hindrances in the usage of any IT system. For instance, security related barriers are those that hinders the particular individual in the usage of IT systems due to security reasons.

The users perceive the psychological factor as a determinant factor next to technological factors in adopting HRIS. It implies that psychologically the user's intention and satisfaction plays an immense role in its adoption. Psychological factors deal with user's perception, complexity in usage and satisfaction.

The mean value of the organisational factors $(M=4.02)$ and environmental factors $(M$ $=4.06$ ) is also reasonably high as it is above the value 4 in a scale of 5. Organisational factors comprise organisation size, top and middle management support, organisation culture and financial infrastructure. Organisation culture is the collective beliefs and values of the people working in the concerned organisation (Schneider, 1990). Financial infrastructure is the firm's financial capability in affording basic facilities, services, and installations needed for the functioning of IT systems.

However the standard deviation of environmental factors is higher than the other factors comparably which depicts that there is variation in the perception of users regarding the environmental factors. Environmental factors are mainly the external pressure, competitiveness and government's commitment from the globalised world which has a direct influence on the adoption of HRIS systems. Competitive pressure is the external pressure that a company faces in the global environment. Government commitment is $t$ how far the government supports the introduction of new IT systems.

Similarly the adoption of HRIS also has a relatively higher standard deviation that depicts that users perceive the adoption factors differently. The above descriptions prove that the factors considered are well taken to measure the adoption of HRIS and gives a satisfactory stance. 


\section{Analysis of difference in perception of various factors based on company size}

One way ANOVA has been administered is to find if there is any significant difference in perception of these factors with respect to size of the company. From Table 3, it can be seen that there is significant difference in the perception of technological factors $(p=0.067)$, organisational factors $(p=0.000)$, environmental factors $(p=0.023)$, psychological factors $(p=$ $0.001)$ and adoption of HRIS $(p=0.003)$ based on the different company size. Three levels of 'company size' are considered for the study, namely small, medium and large size companies.

Table 3: ANOVA of the factors based on size of the company

\begin{tabular}{lrrrcc}
\hline \multicolumn{7}{c}{ Mean values based on company size } & & \\
\hline \multicolumn{1}{c}{ Different Factors } & Small & Medium & Large & F & p value \\
\hline Technological factors & 4.26 & 4.18 & 4.31 & 2.74 & 0.067 \\
Organizational facors & 4.25 & 3.84 & 4.07 & 12.73 & $\mathbf{0 . 0 0 0 *}$ \\
Environmental factors & 4.29 & 3.88 & 4.11 & 3.89 & $\mathbf{0 . 0 2 3 *}$ \\
Pscyhological factors & 4.36 & 3.98 & 4.16 & 7.41 & $\mathbf{0 . 0 0 1 *}$ \\
Adoption of HRIS & 4.36 & 3.89 & 3.98 & 6.00 & $\mathbf{0 . 0 0 3 *}$ \\
\hline
\end{tabular}

* statisticallysignificant $\mathrm{p}$ value

Further analysis of identifying particular differences between small, medium and large scale is done using post hoc test. From Table A1 mentioned in the appendix, it is clear that small, medium and larger companies do not show any difference in the technological factor. This shows that for all the companies, the benefits and barriers are found to be an equally important concern before implementation of any new IT systems. It can be noted that from the Table A2, the mean value of organisation factor is higher for the small scale organisations than large and medium sized companies. This implies that the organisational factors play a major role in adopting to the information systems in the case of small organisations. It is found to be less important for medium size organisations where the mean value is significantly lesser than the other two types of the companies.

Table A3 shows that the mean value $(\mathrm{M}=4.2)$ of environmental factors for small size company has higher value than others which describes that smaller companies have a great influence due to the environmental scenario that includes external pressure, competitiveness and globalisation. Table A4 depicts that the psychological factors score high with small scale companies $(\mathrm{M}=4.36)$ representing that the perception of people in the usage satisfaction and job satisfaction plays a major role in small companies. This may be due to the fact that users in small firms are more comfortable psychologically in adopting to information systems.

It is obvious from the Table A5 that small companies score higher in going for adoption of HRIS. The medium and large companies are found to fall under the same subset, depicting that there is no significant difference between the medium and large companies with respect to the factors that contribute towards adoption of HRIS. This means that medium and large organisations are not as enthusiastic as small organisations in adopting to HRIS, though they are the immediate prospects for such systems. 
The main reasons for increase in usage of HRIS system in larger firms can be substantiated as due to good financial infrastructure, top management support, organisation climate and organisational culture. This clearly shows that the larger company has a great advantage in the adoption of new technology like HRIS and that, smaller firms need to be supported with their requirements to succeed in adoption of technologies, though they are relatively more enthusiastic.

\section{Impact of various factors on adoption of HRIS}

The extent of impact of the four factors on adoption of HRIS was examined using the statistical technique linear regression. Adoption of HRIS is the dependent variable and the factors namely technological factors, organisational factors, environmental factors and psychological factors are the independent variables used in regression. The technique analyses the strength of influence of these four factors in explaining the extent of variance in adoption of HRIS.

The regression results show that these four predictor variables contribute to the adoption of HRIS to the extent of 50.2 percent as in Table 4. Coefficient of determination $\left(\mathrm{R}^{2}=\right.$ $50.2 \%$ ) describes that the factors explain the variance in adoption of HRIS statistically significantly. This depicts that these factors has a significant impact on the adoption of HRIS. Hence the adoption of HRIS can be achieved by influencing these factors.

Table 4: Regression (Model Summary)

\begin{tabular}{rcccc}
\hline Model & $\mathrm{R}$ & $\mathrm{R}$ Square & Adjusted R Square & $\begin{array}{c}\text { Std. Error of the } \\
\text { Estimate }\end{array}$ \\
\hline 1 & $.718^{\mathrm{a}}$ & .515 & $\mathbf{. 5 0 2}$ & .37176 \\
\hline
\end{tabular}

a. Predictors: (Constant), PsychologicalFactor, TechnologicalFactor, OrganisationalFactor, EnvironmentalFactor

Table 5: Coefficients of all the factors

\begin{tabular}{lccccc}
\hline \multicolumn{7}{c}{$\begin{array}{l}\text { Unstandardized } \\
\text { Coefficients }\end{array}$} & $\begin{array}{l}\text { Standardized } \\
\text { Coefficients }\end{array}$ & & \\
\hline Different Factors & $\mathrm{B}$ & $\begin{array}{l}\text { Std. } \\
\text { Error }\end{array}$ & Beta & $\mathrm{t}$ & Sig. \\
\hline (Constant) & -.359 & .492 & & -.729 & .467 \\
Technological factors & .210 & .109 & .124 & 1.926 & .056 \\
Organizational facors & .373 & .109 & $\mathbf{. 2 5 0}$ & 3.430 & $\mathbf{. 0 0 1}$ \\
Environmental factors & .354 & .069 & $\mathbf{. 4 1 1}$ & 5.167 & $\mathbf{. 0 0 0}$ \\
Pscyhological factors & .127 & .097 & .098 & 1.307 & .193 \\
\hline
\end{tabular}

Dependent Variable : Adoption of HRIS

The coefficient table (table 5) shows that environmental factor has the highest impact on the adoption of HRIS than other factors. The table shows that the environmental factor $(\beta=$ $41.1 \%, \mathrm{t}=5.167, \mathrm{p}=0.000)$ influences adoption of HRIS statistically significantly. 
Organisational factor $(\beta=25 \%, \mathrm{t}=3.430, \mathrm{p}=0.001)$ also has significant influence in adoption of HRIS. But the technological factors and psychological factors have relatively less impact on the adoption of HRIS. The beta value depicts the percentage impact of each factor in explaining the variance in the dependent factor; the higher the value, greater is its impact. The t value depicts the path validity towards the dependent variable, and it is statistically significant at 0.01 level of significance if it is more than 1.96. Hence the major influencing factor of 'adoption of HRIS' is the environmental factor.

\section{Discussion}

The results of the study found that the mean value $(M=4.26)$ for technological factor has higher score than other factors. Any technology has both advantages and disadvantages. It is the supplementary gains in using the technology that stimulates a person to rely on particular technology system. The benefits are considered to be a part of an element for using any technology system, because the level of easiness, accessibility, task effectiveness, cost reduction in installation has a great impact in the perception of people using the HRIS system which has been strongly supported by Chong and Ooi (2008).

It is clear that the perception of user's adoption of HRIS largely varies among the different size of the companies. The organisational size contributes to a paramount role in the organisational factor as the capability of the company in using HRIS system relies on the size of the company. The inefficiency of technical expertise in smaller firms may be the reason for its non-adoption of HRIS in smaller firms in the organisational context.

The top and middle management support is the ingredient tool in the organisational factor leading to the adoption of HRIS. Centralisation is the process where the top executive's decision regarding the introduction of new IT systems like HRIS is of crucial nature in the organisational context. It is the top management's direction, control and environmental scanning of the new IT systems that lead to successful adoption of HRIS in organisational scenario. The chief executive's knowledge and attitude also fuels for the top management decision support. The supervisor's direction and training of the employees have major impacts on the employee's successful implementation of a system, which in turn leads to huge profits and success for the company. Clear communication between the employees and the supervisors leads to effective utilisation and implementation of HRIS.

The organisational culture entails the employee's adaptable nature, flexibility in usage of the system and imparts innovative ideas. It has a strong influence on the commitment of the employees which has been previously proved by the Schneider (1990). The top management's commitment is reflected in the extent to which they are obliged towards implementation of the HRIS system. The organisational climate encourages employee involvement and empowerment which predicts the financial success of any organization.

Financial infrastructure is one of the vital tools among organisational factors. The company's capability for financial resource and installation of the available services required for the usage of HRIS systems has great significance as the expenditure for the installation of new IT systems is not only a one-time investment but also includes the cost in maintaining the particular system. 
The study has also depicted that the environmental factor is statistically significant in contributing towards the dependent variable. The main reason is the connectivity and integration prevalent in the globalised business world. It is the legal environment, including the laws and regulations set by the government that has a significant role in the environment context as supported by Oliveira and Martins (2010). As the business laws are framed by the government, its influence has a major effect in its implementation of HRIS. The innovation in new IT systems may stimulate the companies to adopt the new systems to endure in the sustainable business environment. The opening up of new economies, lesser trade barriers and increased share in value chain by liberalisation supported by Ongori and Migiro (2010) has a significant influence on the adoption of HRIS. Hence, it is the environmental factors which persistently affect every organisation's adoption capability. However the readers are also reminded of the varied perception of the environmental factor with a higher standard deviation that depicts that this factor is viewed differently by different lots. This may also indicate the awareness and updating level of distinct units considered for analysis. It is true that every company has to constantly eye watch over the environment's ever changing scenario for its successful adoption of HRIS. Utmost importance can be given to environmental factors as it is a dynamic component for the adoption of HRIS.

The study suggests that the psychological factor is found to be a dominant factor in the adoption on HRIS in small firms. It can be substantiated that the user's perception in smaller companies gives utmost preference to psychological factor as it provides satisfaction and complexity in the usage of HRIS by the users, as previously supported by Kossek (1994) and McAfee (2003). The user's perception and their intention to use a particular new system relies on the how they perceive their new introduction of IT systems and also their intention for fear of replacing their jobs for any new introduction.

The user's satisfaction is one of the components of psychological factor that includes job satisfaction, favourable attitude and removal of personal freedom. The satisfaction of the employees includes inner satisfaction i.e. the favourable attitude and job satisfaction. A higher pay for the employees is also a motivational factor that make them to indulge in implementation of HRIS. The complexity comprises people's difficulty in usage of the new systems without any technical background, fear in its usage and emotional reactions as studied by the authors Yeh (1997) and Brehm (1966). The people who want to sustain with the old system do not accept new technologies or information systems and they react by rejecting the system that may lead to failure of the adoption of HRIS.

The group cohesion has also found to be great impact in its adoption because it leads to greater interconnectedness among the employees or team members paving to greater interaction and adhesion towards their completion of work as substantiated by Steiner (1972). Kavanagh and Thite (2009) argue that it is the leadership qualities like guiding, directing and controlling that play an immense role in successful implementation of HRIS. Because, if the leaders who are not dedicated for the introduction of HRIS may lead to delay and failure resulting in failure of adoption of HRIS.

It clearly depicts that planning is essential for successful adoption of HRIS which gives a lucid picture about the overall capacity of the company to adopt or not which has been 
validated by Kavanagh and Thite (2009). The main reason for the failure of the adoption of HRIS is the people who reject the system and intend to stay with their existing system.

Communication is also one of the components which pave way for effective implementation of HRIS. It is the team leader or the supervisor's responsibility to deliver the new changes for the introduction of HRIS and make them understand its necessity and its usefulness to the employees. Training is another factor that contributes in successful usage of HRIS system because it is the training which helps the employees to develop adequate technical ability (Ruta, 2005). The measures of adoption of HRIS directly influence the factors for the adoption of HRIS, which the organisations need to focus on in order to improve the success rate of implementation of HRIS.

\section{Conclusion}

This study has explored a number of factors that influence in the adoption of information systems and its ease for the HR manager to play the role of a strategic and an effective administrator. HRIS has become an essential tool for the sustenance of an organisation in the globalised environment. From the study, it is portrayed that the four factors namely technological factors, organisational factors, psychological factors and environmental factors and their individual components play a major role in adopting to new technologies. The companies need to focus on all these influences and measures to ensure successful implementation of new systems. All the four factors have their own significant importance, but the role of environmental factors has surpassed the other factors. It conveys the message that the external pressure is a major element that influences adoption of HRIS irrespective of the company size or the individuals or even the technological factors. As this study has focused on information sector, it has a wide scope to be explored in other sectors like manufacturing and automobile to provide more insights regarding transformation towards HRIS. From the results, the practical application for the successful transformation towards HRIS can be achieved focusing on the four major factors discussed and their constituent aspects.

\section{References}

Agrell, A. \& Gustafson, R. (1996). Innovation and creativity in work groups. InHandbook of work group psychology, ed. West, M.A, 317-43. Chichester: John Wiley \& Sons.

Alba, M., Diez, L., Olmos, E. \& Rodriguez, R. (2005). Global performance management for small and medium-sized enterprises. International Federation for Information Processing Book Series, Springer, Boston, MA.

Alshawi, S. (2010). Organisational, technical and data quality factors in CRM adoption: SMEs perspective. Industrial Marketing Management, 40 (3), 376-383.

Banerjee, S. \& Golhar, D.Y. (1994). Electronic data interchange: Characteristics of users and non-users. Information and Management, 26 (2), 65-74.

Barbosa, D.H. \& Musetti, M.A. (2010). Logistics information systems adoption: An empirical investigation in Brazil. Industrial Management \& Data Systems, 110 (6), 787-804.

Bass, B.M., ed. (1998). Transformational leadership: Industrial, military and educational impact. Mahwah, NJ: Lawrence Erlbaum Associates, Inc.

Journal of Management and Development Studies (26) 
Beckers, A.M. \& Bsat, M.Z. (2002). A DSS classification model for research in human resource information systems. Information Systems Management, 19(3), 41-50.

Blanchard, K. (2007). Leading at a higher level. Upper Saddle River, NJ: Prentice Hall.

Brehm, J. W. (1966). A Theory of Psychological Reactance. Academic Press, New York.

Bushman, B. J.(1998). Effects of warning and information labels on consumption of full-fat, reduced-fat and no-fat products. Journal of Applied Psychology, 83, 97-101.

Cavaye, M. \& Hussain, H. (2007). IT alignment and performance in small manufacturing firms. Journal of Strategic Information Systems, 11, 109-132.

Chang, J. \& Cheung, L. (2001). An empirical analysis of the barriers to implementing Ecommerce in small-medium sized construction contractors in the state of Victoria. Construction Innovation, 1, 31-41.

Chau, P. Y. K. \& Tam, K.Y. (1997). Factors affecting the adoption of open systems: An exploratory study. MIS Quarterly, 21(1), 1-24.

Chinyanyu, L. \& Yahsueh, C. (2011). Understanding the determinants of cloud computing adoption. Industrial Management \& Data Systems, 111(7), 1006-1023.

Chong, A. Y. L. \& Ooi, K. B. (2008). Adoption of inter organizational system standards in supply chains: An empirical analysis of Rosetta Net standards. Industrial Management \& Data Systems, 108(4), 529-547.

Correll, B. (2005). Change management: Using the right techniques and technologies to ensure success. IHRIM.link, 12.

Crawford, J. (1998). NEWS - a project to get smaller enterprises on line. Department of Industry, Science and Tourism, Retrieved March 23, 2003, from www.noie.gov.au/publications

Danilewicz, D. (1997). How technology has changed the payroll function. Management Accounting. 78, 6-9.

Davis, F. D., Bagozzi, R. P. \&Warshaw, P. R. (1989). User acceptance of computer technology: a comparison of two theoretical models. Management Science, 35(8), 982-1003.

Decker, M., Schiefer, G. \& Bulander, R. (2006).Specific challenges for small and mediumsized enterprises in M-business.A SME-suitable framework for mobile services. Proceedings of the International Conference on E-Business, 169-74.

DeLone, W. H. (1981). Firm size and characteristics of computer use. MIS Quarterly, 5(4), 6577.

DePietro, R., Wiarda, E. \& Fleischer, M. (1990). The context for change: organization, technology and environment. InTornatzky, L. G. \& Fleischer, M. (Eds), The Process of Technological Innovation, Lexington Books, Lexington, MA, 151-175.

DeSanctis, G. (1986). Human resource information systems: A current assessment. MIS Quarterly, 10, 15-26.

Drescher, S., Burlingame, G. \& Fuhriman, A. (1985). Cohesion: an odyssey in empirical understanding. Small Group Behaviour, 16, 3-30.

Duck, J. D. (2001). The change monster. New York: Crown Business.

Elliot, R. H. \& Tevavichulada, S. (1999). Computer literacy and human resource management: A public/private sector comparison. Public Personnel Management, 28(2), 259-74. 
Evered, E. W., Hartel, C. E. J \& Neale, M. (2001). A longitudinal study of work group innovation: The importance of transformational leadership and morale. Advances in Health Care Management, 2, 315-340.

Goodhue, D. L. (1995). Understanding user evaluations of information systems. Management Science, 41(12), 1827-44.

Hackman, J. R. \& Oldham, G. R. (1976). Motivation through the design of work: test of a theory. Organization behaviour and Human Performance, 16, 250-79.

Hartel, C. E. J. (2008). HR as manager of the human imprint. Encyclopedia of HRIS: Challenges in e-HRM, eds T. Torres-Coronas and M. Arias-Oliva, 1, 457-63.

Hashim, J. (2007). Information communication technology (ICT) adoption among SME owners in Malaysia. The International Journal of Business and Information, 2, 221-240.

Hennessey, H. (1979). Computer applications in human resource information systems. Human Resource Planning, 2(4), 205-13.

Howard, A. (2001). Software engineering project management. Communications of the ACM, $44(5), 23-5$.

Humprey, J. (2001). Opportunities for SMEs in developing countries to upgrade in a global Identifying opportunity, meeting challenges, and measuring success. Proceedings of the 10th Australasian Conference on Information Systems, 532-541.

Iverson, R. D. \& Roy, P. (1994). A causal model of behavioural commitment: evidence from a study of Australian blue-collar employees. Journal of Management Information Systems, 20, 15-41.

Jeon. B. N., Han. K. S. \& Lee. M. J. (2006). Determining factors for the adoption of e-business: The case of SMEs in Korea. Applied Economics, 38, 1905-1916.

Julien, P. A. \& Raymond, L. (1994). Factors of new technology adoption in the retail sector. Entrepreneurship Theory and Practice, 8, 79-87.

Kandel, A. (n.d). The eight fatal flaws of HR system implementation and how to avoid them. Retrieved March 14, 2007, from www.shrm.org/hrtx/library_published/nonIC/CMS_000199.asp

Kannabiran, G. \& Dharmalingam, P. (2012). Enablers and inhibitors of advanced information technologies adoption by SMEs: An empirical study of auto ancillaries in India. Journal of Enterprise Information Management, 25(2), 186 - 209.

Kavanagh, M. J. \& Thite, M. (2009). Human Resource Information Systems, Sage Publications, 195-200.

Kavanagh, M. J., Gueutal, H. G. \& Tannenbaum, S. I. (1990).Human Resource Information Systems: Development and Application, PWS-KENT Publishing Company: Boston.

Keller, R. T. (1983). Predicting absenteeism from prior absenteeism, attitudinal factors and Non attitudinal factors. Journal of Applied Psychology, 68, 536-40.

Kossek, E. E. (1994). Waiting for innovation in HR department Go dot implements a HRIS. Human Resource Management, 33(1), 35-59.

Kwon, T. H. \& Zmud, R. W. (1987). Unifying the fragmented models of information systems implementation. InCritical issues in information systems research, ed. R.J. Boland, Jr. and Hirschheim, R. A., New York: John Wiley, 227-52.

Lederer, A. L. (1984). Planning and developing a human resource information system. The Personnel Administrator, 29(8), 27-39. 
Levy, M., Powell, P. \& Yetton, P. (2001). SMEs: Aligning IS and the strategic context. Journal of Information Technology, 6, 133-144.

Lorenzi, N. M., \& Riley, R. T. (2000). Managing change: An overview. Journal of the American Medical Informatics Association, 7(2), 116-124.

Lowry, G., Singh, M. \& Scollary, A. (1999). Electronic commerce initiatives in Australia, in Identifying opportunity, meeting challenges, and measuring success, Proceedings of the 10th Australasian Conference on Information Systems, 532-41.

Lymer, A. (1997).The internet and small businesses: a study of impacts, Fifth European Conference on Information Systems, Cork Publishing, Cork.

Martinson, M. G. \& Chong, P .K. C. (1999). The influence of human factors specialist involvement on information systems success. Human Relations,52(1), 123-52.

McAfee, A. (2003). When too much IT knowledge is a dangerous thing. Sloan Manage Review, 44, 83-89.

Miller, J. S. \& Cardy, R. L. (2000). Technology and managing people: Keeping the 'human' in human resources. Journal of Labour Research, 21(3), 447-61.

Moore, L. L. \& Clavadetscher, C. J. (1985). Computerized HRIS: Still simmering on the backburner. Personnel, 62(8), 8-11.

Oliveira, T. \& Martins, M. F. (2010). Understanding e-business adoption across industries in European countries. Industrial Management \& Data Systems, 110(9).

Ongori, H. \& Migiro, S. O. (2010). Information and communication technology adoption: A literature review. Journal of Chinese Entrepreneurship, 2, 93-104.

Overman. S. (1992). Reaching for the 21st Century. HR Magazine, 37, 61-63.

Poon, S. \& Swatman, P. M. C. (1999). A longitudinal study of expectations in small business internet commerce. International Journal of Electronic Commerce, 3, 21-33.

Prager, K. P., \& Overholt, M. H. (1994).How to create a changed organisation. Information System Management, 11(3), 64-70.

Rogers, E. M. (2003). Diffusion of Innovations.4th edition, The Free Press, New York.

Ruta, C. (2005). The application of change management theory to HR portal implementation in subsidiaries of multinational corporations. Human Resource Management, 44(1), 3553.

Schneider, B., ed. (1990). Organizational climate and culture. San Francisco: Jossey-Bass.

Seyal, A.H., AbdRahman, M.N. \& HjAwgMohamad, H.A.Y. (2007). A quantitative analysis of factors contributing electronic data interchange adoption among Bruneian SMEs. Business Process Management Journal, 13(5), 728-746.

Shaw, M. E. (1981). Group Dynamics. McGraw-Hill, New York, NY.

Sheth, J. N. \& Sharma, A. (2005). International e-marketing: opportunities and issues. International Marketing Review, 22(6), 611-622.

Shrivastava, S. \& Shaw, J. (2004). Liberating HR through technology. Human Resource Management, 42(3), 201-222.

Singh, H. P., Jindal, S. \& Samim, S. A. (2011). Role of Human Resource Information System in Banking Industry of Developing Countries. Special Issue of the International Journal of the Computer, the Internet and Management, 19, 44.1-44.4.

Srinivasan, R., Lilien, G. \& Rangaswamy, A. (2002). Technological opportunism and radical technology adoption: An application to e-business. Journal of Marketing, 66, 47-61. 
Steiner, I. D. (1972). Group Process and Productivity. Academic Press, New York, NY.

Tan, K., Chong, S., Lin, B. \& Eze, U. (2009). Internet-based ICT adoption: evidence from Malaysian SMEs. Industrial Management \& Data Systems, 109, 224-44.

UNDP (2005). International cooperation at a crossroad: Aid, trade and security in an unequal World. Summary Human Development Report, United Nations Development Programme, New York, NY.

Wainwright, D., Green, G., Mitchell, E. \& Yarrow, D. (2005).Towards a framework for Technology and the Competitive Edge. Academy of Management Executive, 6(2), 7-17.

West, M.A., Patterson, M., Pillinger, T. \& Nickell, S. (2001). Organizational and environmental predictors of innovation. Birmingham: Aston Business School working paper.

Wood, C. M. (2004). Marketing and e-commerce as tools of development in the Asia-Pacific: a dual path. International Marketing Review, 21(3), 301-320.

Yang, K. H., Lee, S. M. \& Lee, S. G. (2007). Adoption of information and communication Technology: Impact of technology types, organizational resources and management style. Industrial Management \& Data Systems, 107(9), 1257-1275.

Yap, C. S. (1990). Distinguishing characteristics of organizations using computers. Information and Management, 18(2), 97-107.

Yeh, C. Y. (1997). Human resource information systems: Implementation in Taiwan. Research \& Practice in Human Resource Management, 5(1), 57-72.

Yesbank (2009). Technology for financial efficiency, YES BANK's Knowledge Banking Publication, 1(1). 


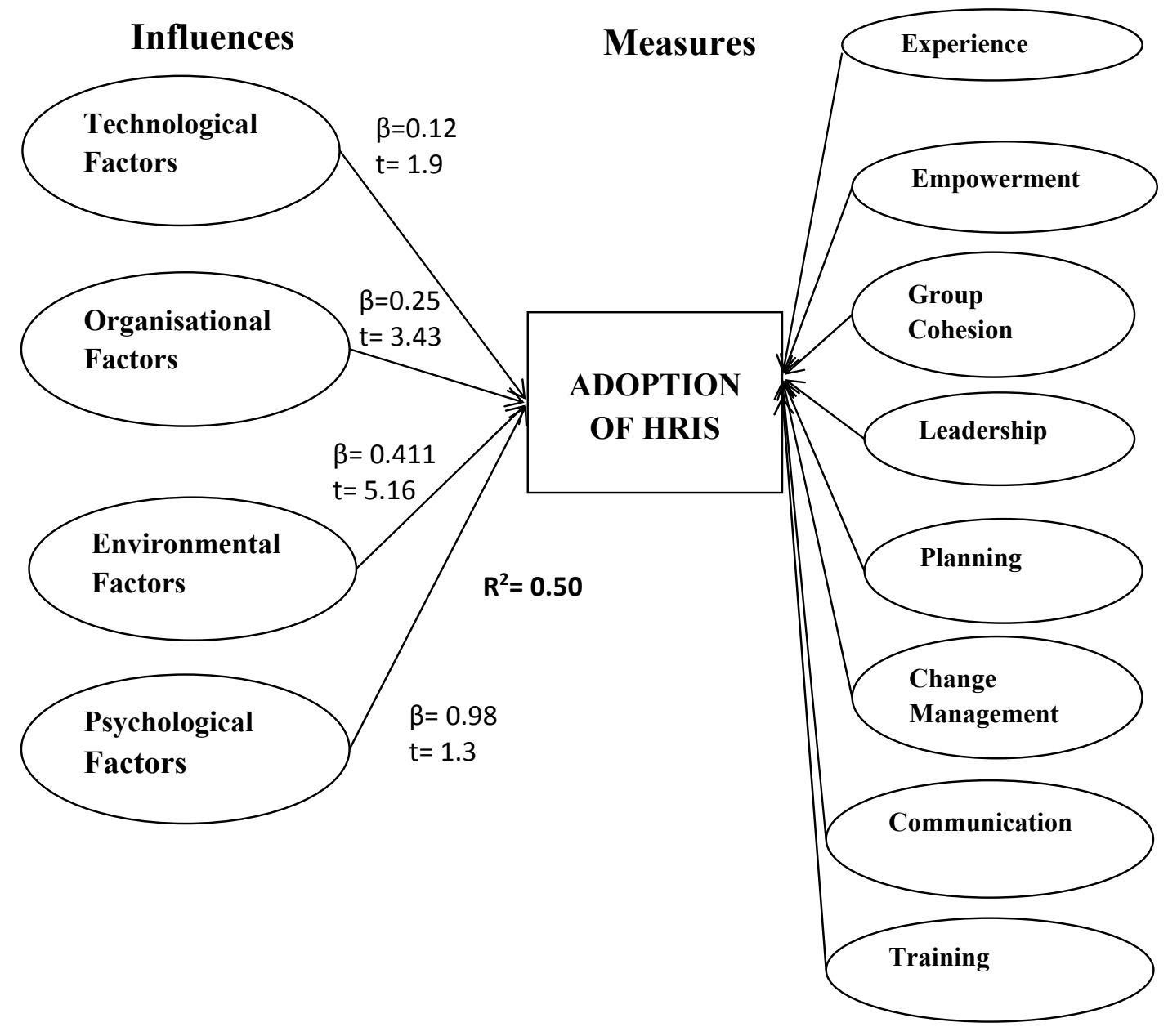

Figure 1: Influences and Measures of Adoption of HRIS 
Table A1: Post hoc tests of technological factor based on size of the company

\begin{tabular}{|c|c|c|}
\hline \multicolumn{3}{|c|}{ Technological Factor } \\
\hline Tukey B & & \\
\hline & & Subset for alpha $=0.05$ \\
\hline Company Size & $\mathrm{N}$ & 1 \\
\hline Medium & 48 & 4.1818 \\
\hline Small & 19 & 4.2679 \\
\hline Large & 83 & 4.3131 \\
\hline
\end{tabular}

Table A2: Post hoc tests of organisational factor based on size of the company

\begin{tabular}{llccc}
\hline \multicolumn{5}{c}{ Organisational Factor } \\
\hline Tukey B & \multicolumn{4}{c}{ Subset for alpha $=0.05$} \\
\hline Company Size & $\mathrm{N}$ & 1 & 2 & 3 \\
\hline Medium & 48 & 3.8476 & & \\
Large & 83 & & 4.0784 & 4.2526 \\
Small & 19 & & & \\
\hline
\end{tabular}

Table A3 - Post hoc tests of Environmental factor based on size of the company

\begin{tabular}{llcc}
\hline & \multicolumn{2}{c}{ Environmental Factor } \\
\hline Tukey B & \multicolumn{2}{c}{ Subset for alpha $=0.05$} \\
\hline & & 1 & 2 \\
\cline { 2 - 3 } Company Size & $\mathrm{N}$ & 3.8837 & \\
\hline Medium & 48 & 4.1124 & 4.1124 \\
Large & 83 & & 4.2982 \\
Small & 19 & & \\
\hline
\end{tabular}


Table A4: Post hoc tests Psychological factor based on size of the company

\begin{tabular}{lccc}
\hline & \multicolumn{2}{c}{ Psychological Factor } \\
\hline Tukey B & \multicolumn{2}{c}{ Subset for alpha $=0.05$} \\
\hline & & 1 & 2 \\
Company Size & $\mathrm{N}$ & 3.9821 & \\
\cline { 3 - 3 } Medium & 48 & 4.1659 & 4.3684 \\
Large & 83 & & \\
Small & 19 & & \\
\hline
\end{tabular}

Table A5: Post hoc tests of Adoption of HRIS based on size of the company

\begin{tabular}{llcc}
\hline & \multicolumn{2}{c}{ Adoption of HRIS } \\
\hline Tukey B & \multicolumn{2}{c}{ Subset for alpha $=0.05$} \\
\hline Company Size & $\mathrm{N}$ & 1 & 2 \\
\hline Medium & 48 & 3.8958 & \\
Large & 83 & 3.9832 & 4.3684 \\
Small & 19 & & \\
\hline
\end{tabular}

